\title{
IMÁGENES DE LA NATURALEZA: RECURSO RETÓRICO DE LA DIVERSIDAD SEMÁNTICA DE LOS SÍMBOLOS EN LA ORESTÍADA DE ESQUILO
}

\author{
María Esther Conejo Aróstegui
}

\begin{abstract}
RESUMEN
Esquilo utiliza imágenes de la naturaleza como el árbol, la semilla, la flor, el fruto, el rocío y otras, en diferentes "niveles" de significado, desde su contexto habitual, y en distintas "transposiciones" a otros contextos, hasta presentar un significado diametralmente opuesto al original. Por medio de estas imágenes, el dramaturgo revela la verdadera naturaleza de las cosas, de los individuos, de sus motivaciones y de las relaciones de unos con otros, así como el ambiente que rodea el desarrollo de las acciones, de una a otra tragedia hasta el desenlace de la trilogía.
\end{abstract}

\begin{abstract}
Esquilo uses images from nature like trees, seeds, flowers, fruit, dew, and others in different "levels" of meaning from their habitual context, and in distinct "transpositions" in other contexts, in order to present a meaning diametrically opposed to the original. Through these images, the playwright reveals the true nature of things, of individuals, of their motivations, and their relations with one another, like in nature, that surrounds the unfolding of the actions, from one to another tragedy until the unraveling of the trilogy.
\end{abstract}

ESQUILO, maestro en el arte de crear imágenes, las emplea profusamente en toda su obra dramática, especialmente en La Orestíada. Entre ellas, las imágenes de la naturaleza constituyen un medio mediante el cual Esquilo expresa plásticamente la profundidad, a la vez que la minuciosidad, de su pensamiento. Si bien emplea la significación más aceptada de una imagen, no se queda allí, sino que busca los significados más recónditos para conferir a su expresión más amplitud, variedad, color, y, por supuesto, más dramatismo.

Conocemos bien la fuerza de los parlamentos y razonamientos esquilianos; sin embargo, el papel de sus imágenes sobresale en importancia porque -en ciertos casos- la imagen tiene más fuerza que la producción verbal, pues permite "ver" (Olerón 1983: 57-9) los acontecimientos e intervenciones de los personajes en una luz especial que a veces revela una motivación escondida o una nueva naturaleza de las cosas. En otras palabras, como diría López-Eire (1995: 153, 158), tienen un valor ilocucionario que no coincide con el semántico, pues las palabras no sólo dicen, sino que también hacen, mueven... La fuerza ilocucionaria depende -por supuesto- de la intención del autor y tiene un propósito pragmático: la persuasión. 


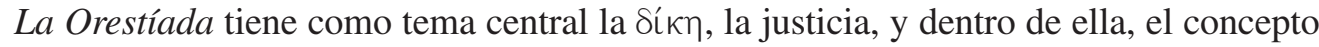
de purificación, tanto ritualista como dramática, es importante. Es un drama de acción humana y divina que se inicia con el crimen y la confusión moral y termina en reconciliación y coherencia ética (Kuhns 1962. La traducción es de la autora). La trilogía se centra en la maldición

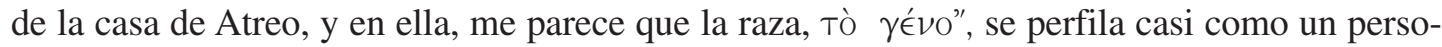
naje subyacente que sufre, mediante las pasiones, los crímenes, las venganzas repetidas y la justicia a través de sus miembros, para salir finalmente purificada y libre en la figura de Orestes.

Esquilo encuentra varias formas de referirse a este $\gamma \in$ É $O^{\prime \prime}$, ya sea con respecto a los ancestros, a los adultos o a la joven generación: la lucha que entre todos ellos se genera es refle-

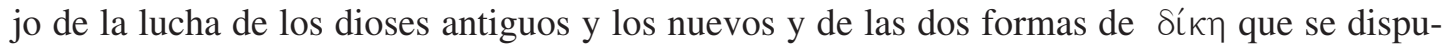
tan a Orestes: la antigua y la nueva.

Los jóvenes son identificados metafóricamente con tres imágenes: đ $\nu \theta \sigma^{\prime \prime}, \quad \epsilon \rho \nu{ }^{\prime \prime}$, $\sigma \pi \epsilon ́ \rho \mu a$ : la flor, el retoño, la semilla. Y aquí da inicio el juego de la distinta significación, que comunica intenciones diferentes -y a veces opuestas-, pues "el contenido meramente semántico puede entrar en contradicción con el pragmático, apoyado en el contexto" (López-Eire 1995: 154).

Examinemos la flor, ese símbolo del amor y de la armonía, atributo de la primavera, de la juventud, que, sin embargo, aparece en el Agamenón, desde el inicio, asociada a la muerte. El coro de ancianos de Argos, por ejemplo, describe cómo los vientos contrarios y las dilaciones

secan y destrozan la flor de los $\operatorname{argivos}^{1}$

y se quejan de que la juventud que se fue a Troya volvió como "cenizas". Menciona igualmente el coro, más tarde, con clara intención acusatoria,

las casas que florecen al orgullo y al peligro. ${ }^{2}$

El rey Agamenón, al bajar triunfante de su carro, termina de llenar la ya rebosante copa de amargura de Clitemnestra, su reina, al pedirle, presentándole a la princesa Casandra:

recibe benévola a esta extranjera:

esta exquisita flor de mi armada, donada por mi ejército. ${ }^{3}$

Casandra misma, antes de morir a manos de la reina, arroja al suelo su $\sigma \tau \epsilon \phi \eta-s u$ guirnalda- y su cetro, que la distinguían como profetisa. Y un último ejemplo: Agamenón, diez años antes, había sacrificado a su hija a los dioses para obtener vientos favorables; en ese preciso momento, Clitemnestra decidió matarlo, si algún día volvía. El má $\theta$ o" y el horror de ese sacrificio son vivamente descritos por el coro. Esquilo desea que notemos lo que la madre de la niña debe de haber sentido (Hamilton 1958: 154). Ifigenia -la hija sacrificada por el padre para satisfacer sus afanes bélicos- es descrita por su madre como

el amado retoño del amor de este hombre y mío; ${ }^{4}$

pero tanto el retoño como el amor están muertos. Esquilo ha escogido connotaciones contrarias al significado usual de la palabra, y las imágenes son símbolo del mundo oscuro y 
siniestro en que se desarrolla el Agamenón. Se evidencia aquí que "en las palabras existe una información semántica y una pragmática, porque la lengua tiene una enorme facilidad de adaptarse a las más diversas situaciones de comunicación, dando nuevos valores a la palabra viva" (López-Eire 1995: 169). En el mundo del Agamenón, el plano divino (la voluntad

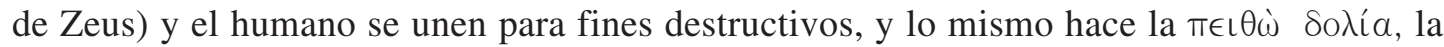
persuasión engañosa, invocada por el coro y empleada por Clitemnestra con gran maestría (Kitto 1939: 104).

Con las imágenes de la semilla ocurre otro tanto: símbolo de las vicisitudes de la vegetación, también simboliza, en el hombre, la alternancia de la vida y la muerte, de la vida en el Hades y de la vida en la luz (Chevalier 1982). Con dos cortos ejemplos basta para ilustrar su empleo. El primer ejemplo se refiere a los troyanos: el heraldo de Agamenón reporta al pueblo de Argos:

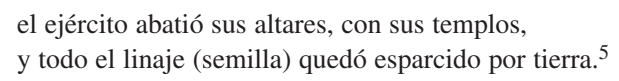

La semilla, de la cual se espera que renazca una nueva generación, ha quedado exterminada. En el segundo ejemplo, el coro de ancianos, al reflexionar sobre las leyes de Zeus, dice:

Al que hizo mal, el pago justo. Norma divina es. ¿Quién, entonces,

de esta mansión expulsará la semilla execranda del crimen? ${ }^{6}$

Una semilla dentro de otra: la semilla del crimen embebida en la raza de los Atridas. No se vislumbra solución.

Esquilo escoge igualmente imágenes naturales para resaltar, en forma irónica, algún hecho, precisamente por el contraste que crea. Estas aparecen especialmente en los parlamentos de Clitemnestra que, por su carácter férreo y desafiante, dice mucho más de lo que las meras palabras significan, por medio de simbología ambigua. Uno de estos casos es el siguiente: al principio de la obra, el coro se describe a sí mismo diciendo:

¿Qué es un viejo sino un árbol sin frondas? ${ }^{7}$

Más tarde, Clitemnestra retoma la imagen para describir la situación familiar exclamando:

mientras el árbol su raíz conserva incólume,

su fronda habrá de extenderse para abrigar la vieja mansión. ${ }^{8}$

Este pensamiento podrá halagar y engañar al soberbio Agamenón, pero en realidad la raíz de este árbol no se conserva incólume y su fronda no habrá de extenderse. Si el árbol es fuente de vida en su simbolismo habitual, en el Agamenón la imagen es preludio de muerte. Y la reina termina su idea, agregando con cargada ironía: 
Sin embargo, lo que Zeus ha madurado para Agamenón es algo muy distinto; en cambio, Clitemnestra cree contar con la aprobación del dios a sus designios.

No obstante, no todo es ambiguo con la reina. También puede presentar con imágenes clarísimas y elocuentes su pensamiento y su estado de ánimo. Al final de la obra, al narrar al coro los hechos, les describe:

Saltó hacia mí su negra sangre y me ha cuajado de gotas... Cuán gratas,

cuán amables para mí, más que el rocío que envía Zeus para mudar la flor en fruto. ${ }^{10}$

El rocío, símbolo de la bendición del cielo, de la juventud y el amor (Martín 1972: 25868), aquí simboliza el odio de una mujer: el odio de la madre traicionada, el odio de la esposa traicionada. El dramaturgo "no está simplemente informando, sino exponiendo también un estado de cosas e invitando a su auditorio a unirse a él en la contemplación de lo narrado". Su intención es "que (el espectador) se introduzca en el estado de cosas que expone y que lo valore y se haga partícipe de su asombro, su terror ante el asunto"(Pratt. En López-Eire 1995: 175).

El contradictorio significado de la terrible imagen es tan impactante que provoca fuertes emociones en el coro que, horrorizado, la interpela:

¿Qué veneno, oh mujer, maléfico,

sacado de frutos de la tierra,

has bebido para tener tal audacia? ${ }^{11}$

Nuevamente, se trastoca la semántica: la tierra, símbolo de fecundidad, produce frutos maléficos.

En estos pocos ejemplos de imágenes de una naturaleza descompuesta que hemos visto, hay temas recurrentes que reflejan un mundo dislocado y confuso que es el mundo del Agamenón.

El mundo de las Coéforas es diferente, aunque en muchos aspectos es un espejo del Agamenón. Algunas de las imágenes se mantienen con cierto grado de negatividad: "los muertos matan a los vivos"; otras se suavizan o quedan en una ambivalencia, mientras que otras se dirigen decididamente hacia lo positivo. El coro se encarga de mantener algunas de esas imágenes, repitiendo: "Infortunio embebido en esta raza", "Herida que derrama sangre", pero la joven generación tiene esperanza y lucha por ella, sobre todo Electra, quien piensa que los dioses

pueden dar un rayo de luz, un germen de vida que se convierta en árbol frondoso. ${ }^{12}$

Por primera vez se emplea la expresión "germen de vida" en su significación primaria, sin dobles sentidos ni transposiciones: el árbol frondoso es una esperanza futura. La combinación de imágenes transmite la esperanza de que la raza no se extinga y que, preservada en Orestes y en la misma Electra, vuelva a echar raíces. Y, efectivamente, cuando ella encuentra al hermano perdido, lo llama 
Orestes, por su parte, invoca la ayuda de Zeus:

¡Hijos sin padre, de su hogar expulsos! ¿Vas a dejar que muera esta cría? Seca hasta sus raíces la progenie de reyes, no ha de haber quien te rinda el homenaje de las hecatombes. ${ }^{14}$

Así, Orestes expresa temores, pero tiene esperanza.

Las imágenes relacionadas con la tierra, tan tenebrosas en el Agamenón, alternan en Las Coéforas con otras más alentadoras: Electra se dirige a la tierra como a un ser benéfico:

Oiga también la tierra que a todo ser cría y nutre

y vuelve a recibirlos como germen fecundo... ${ }^{15}$

Sin embargo, el coro acota un poco más tarde:

Innúmeros males la tierra cría,

fuentes de horror y pena... ${ }^{16}$

Encontramos, entonces, en esta obra, una contraposición en los significados y también una ambigüedad intencional. El mismo coro, después de la muerte de Clitemnestra, exclama:

¡Ay, ay, el tiempo corre y el crimen da sus frutos! ${ }^{17}$

La frase, que se refiere a los frutos recogidos por la reina, que ya ha pagado sus crímenes, también podría referirse -como creo que lo hace- a Orestes, que en ese mismo instante comienza a recoger los suyos al ser asediado por las Erinias, las diosas vengadoras de la sangre derramada.

Coéforas viene a ser como el centro de la balanza que equilibra las fuerzas y las imágenes. En el Agamenón todo era oscuro y conflictivo; en esta segunda pieza las cargas se reparten; en la tercera, se inclinarán hacia las soluciones y la recuperación de lo que yo llamaría la "naturalidad".

La última parte de la trilogía, Las Euménides, tiene, en su primer cuadro, poquísimas imágenes de la naturaleza. En Delfos, la Pitia describe a Orestes, que lleva en sus manos un ramo de olivo de suplicante: es un ramo de esperanza. Por otro lado, Apolo describe a las Erinias como "ovejas sin pastor" que habitan un lugar "donde se mata en flor la semilla viril de varones". Esquilo aquí dramatiza, plásticamente, el choque entre dos clases de justicia, y entre los dioses jóvenes y viejos, problemas que se resolverán -al mismo tiempo o poco después que el de Orestes- en la segunda parte de la pieza. Y es aquí donde el dramaturgo pone en manos de Atenea, la diosa de la sabiduría, la resolución de todos los conflictos de la trilogía.

Ya sabemos que se da el juicio de Orestes (con unas muy cuestionables aseveraciones sobre la paternidad -en las que no vamos a entrar-) en presencia del Areópago, y que es absuelto por obra de Apolo y Atenea. Con esta acción, la maldición de la Casa de Atreo cesa. Pero el tema central de la obra, la justicia, no se agota allí. Atenea ha instituido un nuevo orden jurídico en Atenas, y como consecuencia, las Erinias amenazan la ciudad. Es aquí donde Atenea emplea dos poderosas armas para lograr la concordia: la recta persuasión y la paciencia. 
¿Y cómo logra la diosa hacer efectiva esa persuasión? Atenea, en medio de sus argumentos,

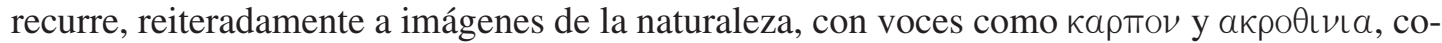
mo $\alpha \nu \theta o^{\prime}, \quad \epsilon \rho \nu o^{\prime \prime}, \sigma \pi \epsilon ́ \rho \mu \alpha$, todos con el sentido "natural' que los caracteriza, con lo cual revierte las imágenes distorsionadas de las piezas precedentes. Al tratar de propiciar a las antiguas diosas, ofreciéndoles repetidamente una posición de honor en el culto de la ciudad de Atenas, las imágenes, como las acciones, van tomando su significación natural en los distintos ámbitos: moral, legal, religioso.

Todas las primicias $(\alpha \kappa \rho \circ \theta \iota \nu \iota \alpha)$ de este país inmenso,

todos los frutos que en el lecho nupcial rinde la vida, son para ti. ${ }^{18}$

Y las flores y los capullos adquieren la significación de una juventud sana: la juventud ateniense masculina y femenina; los frutos de la tierra, vegetales, animales y humanos vuelven a ser normales. Las Erinias, finalmente, dan su "bendición":

\footnotetext{
¡Nunca a los árboles hiera la tormenta! Nunca la ardiente fuerza del fuego solar consuma los capullos nacientes. Den a luz siempre dos hijos las ovejas. $\mathrm{Y}$ de la tierra brote la riqueza sin fin que dé prosperidad a esta tierra. ${ }^{19}$
}

\section{Y Atenea agrega:}

Así su estancia entre nosotros hará que brote siempre un ramo de flores varoniles de dicha sin término. ${ }^{20}$

La luz vuelve a brillar y las antorchas, llevadas por "la flor femenina guardiana de los templos" de Atenea, alumbran el camino hacia el nuevo hogar de las Erinias, ahora Euménides, en el templo mismo de la diosa.

Esquilo demuestra, con el variadísimo uso de sus imágenes, que las palabras no tienen "una significación estricta y unívocamente definida, sino que tienen una plasticidad, una pluralidad de significación, una ambigüedad, que permite comunicar las más diversas intenciones" (Olerón 1983: 61). En las tres piezas de la Orestíada, Esquilo utiliza imágenes de la naturaleza en diferentes "niveles" de significado, revelando plásticamente la realidad de las cosas en el mundo cambiante en que se desarrolla la trilogía. Partiendo de un mundo oscuro y revuelto en que las imágenes escogidas se presentan, en concordancia con él, siniestras y ambiguas, se llega al final, en Euménides, por medio de un giro total de la simbología, a un mundo luminoso y develado. Pero no sólo se revela el ambiente que rodea la obra. Al mismo tiempo, Esquilo vislumbra el pensamiento verdadero e íntimo de los personajes, sus motivaciones inconfesables y las intrincadas relaciones y sentimientos encontrados que subyacen -pero se revelan- en las palabras de unos y otros. 


\section{Notas}

1. Agamenón: 196-7

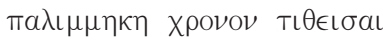

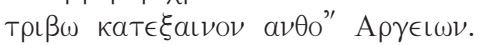

2. Agamenón: 377

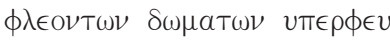

vтte $\rho$ TO $\beta \in \lambda T L \sigma T O V$

3. Agamenón: 954-5

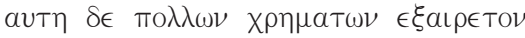

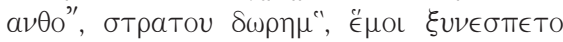

4. Agamenón: 1525-6

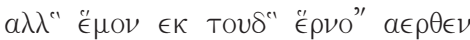

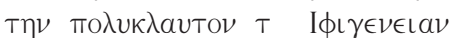

5. Agamenón: 527-8

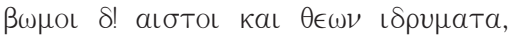

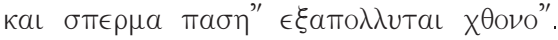

6. Agamenón: 1564-6

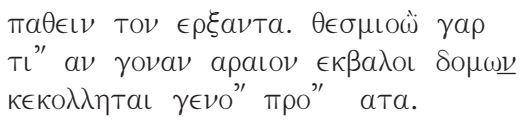

7. Agamenón: 79

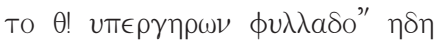

8

Agamenón: 966-7

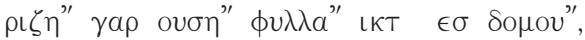

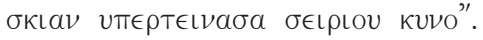

9. Agamenón: 970-1

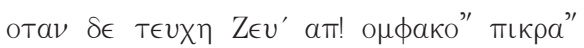

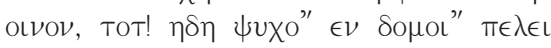

10. Agamenón: 1389-91

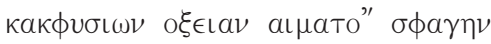

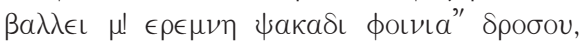

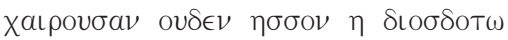

11. Agamenón: 1407-9

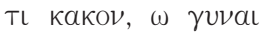

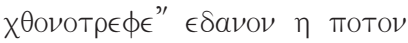

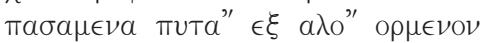

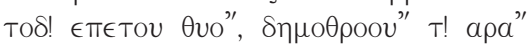

12. Coéforas: 203-4

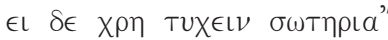

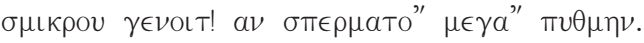


13. Coéforas: 235-6

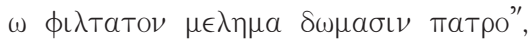

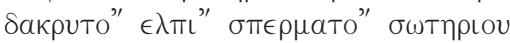

14. Coéforas: 258-61

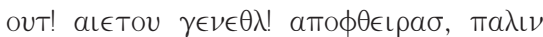

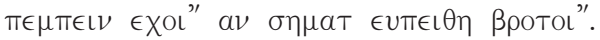

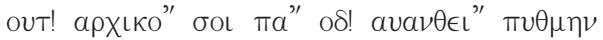

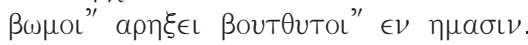

15. Coéforas: $126-8$

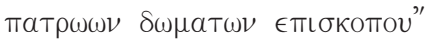

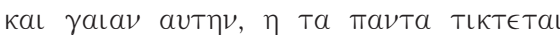

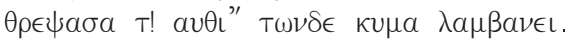

16. Coéforas: 585-6

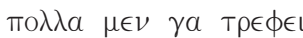

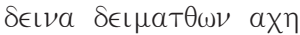

17. Coéforas: 1008-9

alal, alal,

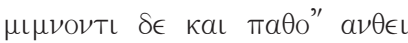

18. Euménides: 834-6

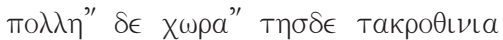

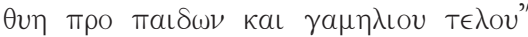

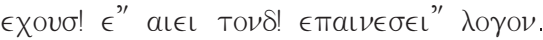

19. Euménides: 937-48

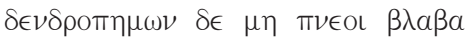

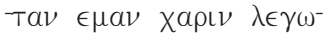

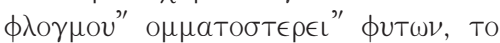

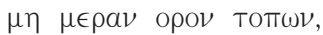

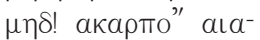

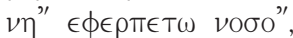

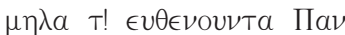

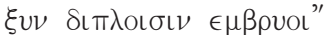

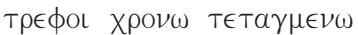

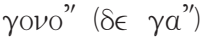

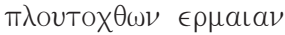

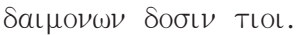

20. Euménides: 1030-1

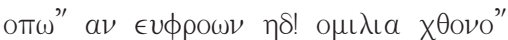

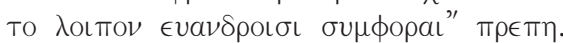

\section{Bibliografía}

Aeschyli. 1966. Septem quae supersunt tragediae. Recensuit Gilbertus Murray. London: Oxford University Press. 
Aeschylus. 1960. Greek Tragedies. Vol. 1 y 3. David Grene and Richmond Latimore (Eds.) Chicago: The University of Chicago Press.

Benac, Henri. 1961. Guide des idees litteraires. Paris: Hachette.

Chevalier, Jean et Alain Gheerhardt. 1982. Dictionnaire des Symbols, Robert Paris: LaffoutJupiter.

Esquilo. 1982. Las Siete Tragedias. México: Porrúa.

Hamilton, Edith. 1958. Three Greek Plays. New York: WW Norton \& Co. Inc.

Kitto, H.D.F. 1939. Greek Tragedy, London: Methuen \& Co. Ltd.

López-Eire, Antonio. 1995. Actualidad de la Retórica. Salamanca: Hespérides.

Martín, J. Luis. 1972. Crítica estilística. Madrid: Gredos.

Oleron, Pierre. 1983. L'argumentation. Paris: PUF.

Morier, Henri. 1961. "Dictionnaire de Poétique et de Rhetorique". Paris: PUF.

Kuhns, Richard. 1962. "The House, the City and the Judge", Bobbs-Merrill Co. Inc., Indianapolis. 